\title{
Observational variations in the seasonal freezing depth across China during 1965-2013
}

\author{
Kun Xia*, Bin Wang \\ State Key Laboratory of Numerical Modeling for Atmospheric Sciences and Geophysical Fluid Dynamics, \\ Institute of Atmospheric Physics, Chinese Academy of Sciences, Beijing 100029, PR China
}

\begin{abstract}
Long-term changes in the soil freezing-thawing depth are an important indicator of climate change. Based on data from 764 meteorological stations across China, we analysed the climatology and variability in the seasonal freezing depth (SFD) during 1965-2013 and investigated the connections among changes in the SFD, meteorological factors (temperature, precipitation, snow depth, freezing index and thawing index) and atmospheric circulations (East Asian winter monsoon [EAWM] and North Atlantic Oscillation [NAO]) in each of 4 sub-regions: northwestern China (W), the Tibetan Plateau (TP) and eastern China (E1 and E2). In addition, the contributions of 2 different factors to variation in the SFD were quantified. The results revealed that during 1965-2013, the SFD noticeably changed from positive to negative anomalies in approximately 1988 for all of the studied regions, exhibiting a significant decreasing trend at rates (mean $\pm \mathrm{SE}$ ) of $0.23 \pm 0.03,0.08 \pm 0.01,0.26 \pm 0.03$ and $0.24 \pm 0.03 \mathrm{~cm} \mathrm{yr}^{-1}$ in E1, E2, W and TP, respectively. The air freezing index was strongly correlated with the SFD in the E2 and TP regions, and accounted for 82.6 and $84.9 \%$ of the change in SFD, respectively. Snow depth showed a significant association with the variability in SFD only in the E1 region. Compared to the NAO, the EAWM plays an important role in changes in SFD. These findings have implications for further understanding the mechanisms of cold environment changes across China.
\end{abstract}

KEY WORDS: Seasonal freezing depth $\cdot$ Variability $\cdot$ Snow depth $\cdot$ Freezing index

\section{INTRODUCTION}

Frozen soil is the product of energy exchange between the atmosphere and lithosphere and is one of the most important components of the cryosphere. Frozen soil is not only susceptible to, but also amplifies, climate change and environmental variability (Zhang et al. 2001). Globally, China is the country with the third-largest area of frozen soil. Seasonally frozen soil and permafrost cover approximately $76.8 \%$ of all land in China. The seasonally frozen soil is mainly distributed across areas above $27^{\circ} \mathrm{N}$. The permafrost includes high-latitude and high-altitude permafrost; the former is mainly located in northern Northeast China, and the latter is mainly distributed in the Tibetan Plateau and high mountain areas in eastern

${ }^{*}$ Corresponding author: xiakun@lasg.iap.ac.cn and western China (Zhou et al. 2000). The variability in frozen soil affects the allocation and exchange of energy and water between different soil layers and between the land and atmosphere, ultimately influencing summer precipitation changes in China and even climate change on a large scale (Shukla \& Mintz 1982, Gao et al. 2005). The variability in frozen soil also has a significant impact on the water resource balance and could affect the ecosystem balance because the high-cold ecosystem depends on the existence of frozen soil (Nelson et al. 2001, Nelson 2003). In addition, many engineering projects exist in the frozen soil regions of China, including the Qinghai-Tibet railway and the China-Russia crude oil pipeline project. The processes of freezing and thawing are accompanied by frost heaving and thaw col-

(C) The authors 2020. Open Access under Creative Commons by Attribution Licence. Use, distribution and reproduction are unrestricted. Authors and original publication must be credited. 
lapsing deformation, threatening the safety of engineering construction. Therefore, research related to frozen soil variability across China has been a focus and has significant implications for making policies to adapt to changes in climate and environment.

During the past few decades, numerous studies related to changes in the near-surface freeze/thaw state have been carried out. Most studies defined the changes in the first date, last date and duration of the soil freeze by using the observational daily/monthly air/soil temperature or mean gridded air temperature. Based on such data, the soil freeze depth was estimated according to the $0^{\circ} \mathrm{C}$ isotherm or calculated by the Stefan solution to investigate the response of the soil freeze depth to climate change (Li \& Chen 2013, Luo et al. 2014, Park et al. 2014, Wang et al. 2015, Peng et al. 2016, 2017). In fact, the actual soil freezing-thawing process has no fixed freeze-thaw critical temperature, and when the soil begins to freeze or thaw is related to the soil texture, soil water content and soil/air temperature (Xia et al. 2011). Therefore, the use of the observational soil freezing depth data is much closer to reflecting the real soil freezing/melting state. However, few studies have used daily/monthly observational freezing depth data due to the sparse observational stations (Shiklomanov 2012, Chen \& Li 2008, Wang et al. 2019, Zhang et al. 2019). For instance, Chen \& Li (2008) and Wang et al. (2019) used approximately 320 and 350 stations across China, respectively, to investigate the spatial distributions and temporal variations in the near-surface soil freeze states.

In addition, 2 other methods have been applied to estimate and predict long-term changes in the near-surface soil freeze/thaw cycle at the continental or global scale. One method is numerical simulation by statistical or physical models (Flerchinger \& Saxton 1989, Slater \& Lawrence 2013, Cuo et al. 2015). However, due to the complexity of the physical processes within permafrost and frozen ground, it remains difficult to accurately simulate soil temperature and moisture during freeze-thaw periods (Nicolsky et al. 2007, Dankers et al. 2011, Rawlins et al. 2013). The other method involves satellitebased remote sensing measurement. In particular, passive microwave remote sensing has high temporal resolution and all-weather capabilities (Zhang et al. 2011, Zhao et al. 2011, Li et al. 2012, Singh et al. 2013), but it is strongly affected by the heterogeneity of the surface, especially that of complex terrain.

Although the methods used by previous researchers are different, the qualitative conclusions of frozen soil variations over China are consistent with each other. However, the quantitative results show fairly large discrepancies and thus need to be verified by more 'true' seasonal freezing depth (SFD) data. For example, Peng et al. (2017) employed the Stefan solution and the observational air temperature from approximately 730 stations across China during 1967-2012 and found that the rate of decrease in the SFD is $0.18 \mathrm{~cm} \mathrm{yr}^{-1}$. Wang et al. (2019) used the observational maximum SFD from approximately 350 stations in China and concluded that the SFD decreased at a rate of $0.41 \pm 0.06 \mathrm{~cm} \mathrm{yr}^{-1}$ over 1961-2010, which is a much higher rate than that reported by Peng et al. (2017).

In addition, in previous studies the causes of near-surface freeze/thaw state changes across China were attributed to environmental and meteorological factors, such as air temperature, latitude, altitude, vegetation growth and urbanization (K. Wang et al. 2015, Peng et al. 2016, X. Wang et al. 2019). Although many studies have shown that snow depth (SND) in Russia has an important influence on the SFD (e.g. Frauenfeld et al. 2004, Park et al. 2015), Peng et al. (2017) found that the SND has no relationship with the SFD across China due to the high spatial heterogeneity of the SFD and SND, so it is necessary to further divide China into different regions for analysis. Furthermore, many meteorological factors are driven and integrated by atmospheric circulation. Frauenfeld \& Zhang (2011) found that the strong decrease in the SFD of the Eurasian high latitudes during the 1970s to 1990s has a strong relationship with the North Atlantic Oscillation (NAO). Meanwhile, in China, the East Asian winter monsoon (EAWM) is one of the most pronounced climate systems and a major factor in modulating wintertime surface air temperatures. However, few studies have examined the correlation between large-scale atmospheric circulation (NAO/EAWM) and SFD across China.

The primary aims of this study were to (1) analyse the variability in SFD in each of 4 subregions across China during 1965-2013 by using the observational maximum freezing depth data from much denser ground-based stations compared to previous work and provide quantitative results of changes in SFD, and (2) comprehensively analyse the correlations of changes in SFD with observational meteorological factors (temperature, precipitation, SND, freezing index and thawing index) and atmospheric circulation, and quantify the contributions of different factors to SFD. 


\section{DATA AND METHODS}

We used observational data of the monthly maximum SFD from the China Meteorological Administration (CMA). SFD monitoring was conducted once per day (08:00 h Beijing Time) by trained professional technicians at all meteorological stations across China with established and uniform guidelines provided by the CMA (2007). During the freezing period, SFD was measured with a frozen soil apparatus that was buried in the ground and its inner tube filled with distilled water. The length of the standard tube varied from 50 to $450 \mathrm{~cm}$ according to the maximum SFD that may appear locally. The upper and lower depths at which the water freezes into the ice are documented as the daily SFD. The monthly maximum SFD was derived from all of the daily SFD data for each month. Observations are available from 2479 stations located throughout China; the observational period ranges from when the station was first built to 2013. The period of records at each station varies: that of the oldest observatory dates back to 1951, while that of the newest starts in 2012, and most stations were built between 1950 and 1960. Additionally, considering the history of the observational stations, the periods of data collection at the stations are not consistent, which may be caused e.g. by removing stations or because the observational records exceed the maximum range of the standard frost tube etc.. For the period 1965-2013, the number of stations without missing values is 626 , and there are approximately 150 stations with values missing only in summer (June, July and August) of each year. Among these 150 stations, ca. 10 stations are located in the Daxing'an and XiaoXing'an Mountains. According to Wang et al. (2019), the latest last date of the soil freeze occurs in the Daxing'an and XiaoXing'an Mountains in about June or July, while for other seasonally frozen soil areas across China, SFD generally equals 0 in summer; thus, it was considered acceptable to include these stations in a calculation of the long-term mean.

Strict data quality control was performed to ensure the consistency and reliability of the results by station and year. First, we identified the outliers at 3 standard deviations from their long-term mean monthly data as questionable data and then compared the outliers with the data from the surrounding stations within $200 \mathrm{~km}$. The questionable data were removed from the time series when all the data in the neighbouring stations were classified as normal; otherwise, the questionable data were retained if at least 2 or more neighbouring stations also had data points $\geq 3$ standard deviations from the mean (Polyakov et al. 2003, Park et al. 2014, Wang et al. 2015). Second, SFD anomalies were calculated relative to the average over the 1965-2013 period for each month to remove the annual cycle; this approach could avoid problems caused by using absolute values, which are influenced by the different station locations and methods used to calculate the monthly or annual mean values. If all observed monthly maximum SFD values equal 0 from 1965-2013 at a station, then this station was considered to have no seasonal frozen soil and was removed from the data set. To ensure that the entire cold season is captured in the calculation, the annual mean SFD was computed from July of one year to June of the next year (Frauenfeld et al. 2007). Meanwhile, in order to facilitate the comparison between different variables, the variables were normalized, i.e. standardized with respect to their mean and standard deviation. Finally, for the 1965-2013 period, 764 stations were screened, and their distribution is shown in Fig. 1. Many observational stations are located in central and eastern China, and few stations are located west of the Tibetan Plateau and in northern Tibet. Therefore, this work is mainly focussed on the seasonally

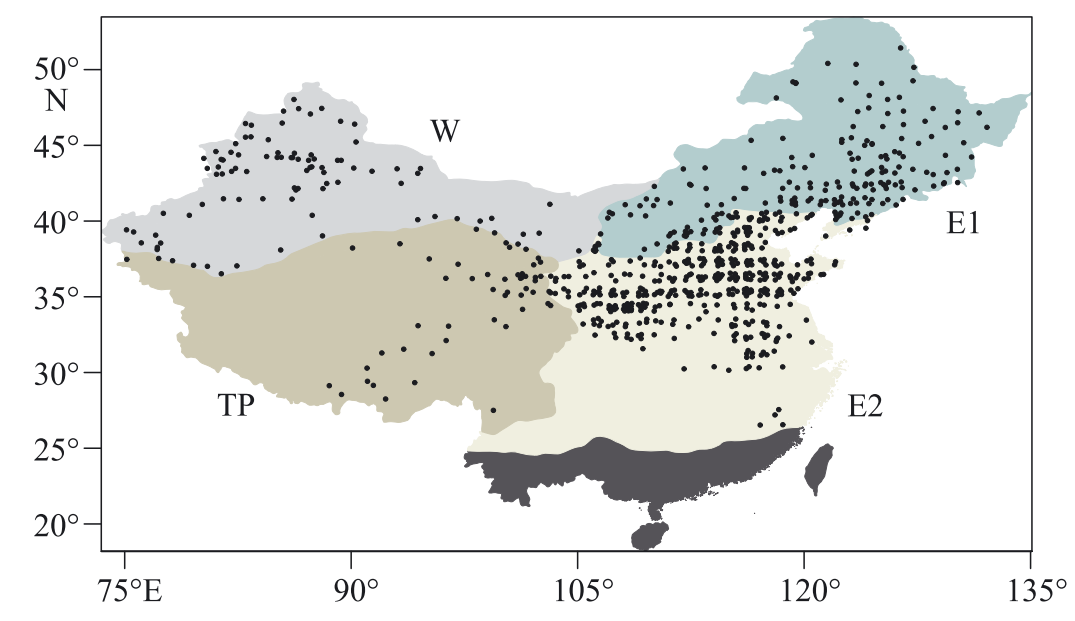

Fig. 1. Distribution of ground-based stations (black circles) and 4 frozen ground regions across China. The 4 regions are located in northwestern China (W), the Tibetan Plateau (TP) and eastern China (E1 and E2) (consistent with Zhou et al. 2000a) 
freezing depth variations distributed in these regions across China.

To compare the regional difference in variability of the SFD, the whole study region was divided into 4 sub-regions according to the Geocryological Regionalization and Classification Map of the Frozen Soil in China provided by the Tibetan Plateau Data Center (Zhou et al. 2000b). One region is located in northwestern China (abbreviated as W; 90 stations), and the second region is in the Tibetan Plateau (TP; 51 stations). The last region is located in eastern China and is further divided into E1 (195 stations) and E2 (428 stations) according to whether the SFD is more than $1 \mathrm{~m}$ (Fig. 1).

In addition, we also used observational data of air temperature (Temp), precipitation (Pre) and SND, which were processed in the same manner as the SFD data. The freezing index (FI) and thawing index (TI) were also calculated according to the observational data of Temp. The FI (TI) is defined as the cumulative degree-days of air temperatures below (above) $0^{\circ} \mathrm{C}$ in the course of a cold (warm) season; the cold season spans 1 July of one year to 30 June of the following year to keep the FI calculated in a continuous cold season, while the warm season spans 1 January to 31 December (Frauenfeld et al. 2007, Wu et al. 2011). To explore the effect of atmospheric circulation on the SFD variability across China, we used NAO and EAWM data. Based on the regional potential vorticity intrusion on the $300 \mathrm{~K}$ isentropic surface, an index of the EAWM (EAWMI) was obtained (Huang et al. 2016). A larger EAWMI indicates a strong cold air and a lower air temperature, which is beneficial to thick frozen soil. Furthermore, the NAO winter index is calculated according to the difference in normalized pressures between Lisbon, Portugal, and Stykkisholmur, Iceland (Hurrell 1995).

The Mann-Kendall test for monotonic analysis of trends together with nonparametric Sen's slope estimator was used to investigate the trends in the SFD. This method has been used in detecting monotonic trends in hydrometeorological time series (Sheffield $\&$ Wood 2008, Dorigo et al. 2012). In addition, to quantitatively assess the contributions of 2 drivers to the SFD change, a widely used method was adapted (Cheng et al. 2015, Wang et al. 2016). We first considered the influence of each factor on the change in SFD, and then chose the factors that have largest correlation with SFD, and little correlation with other chosen factors. This resulted in the selection of FI and SND/Pre for different regions (details in Section 3.2). Based on a multiple linear regression, the SFD can be approximately expressed as follows:

$$
\mathrm{SFD}^{\prime}=a \times \mathrm{FI}+b \times \mathrm{SND}+c
$$

where FI and SND are the time series of the annual mean freezing index and snow depth, $a$ and $b$ are the regression coefficients, and $c$ is a constant. SFD' is the regressed SFD, which can be roughly determined as the SFD caused jointly by FI and SND/Pre. The first term on the right of Eq. (1) can roughly serve as the FI-induced component. The contribution of the change in the FI to the change in the SFD was calculated using equation (2):

$$
\text { C_FI }=(a \times \Delta \mathrm{FI}) / \Delta \mathrm{SFD}^{\prime} \times 100 \%
$$

where FI and SFD' are the changes in the mean FI and SFD' between the first and last 5 yr. The contributions of the changes in the SND/Pre to the changes in the SFD (C_SND or C_Pre) can be obtained in the same manner. The contribution is relative, which means that the sum of C_FI and C_SND/C_Pre is equal to $100 \%$. The SFD component solely forced by FI (or SND/Pre) can be obtained by using a simple linear regression between SFD and FI (or SND/Pre). Pearson correlation analysis was used to calculate the correlation coefficients among SFD and other variables (Temp, Pre, SWD, FI and TI).

\section{RESULTS AND DISCUSSION}

\subsection{Climate state and inter-annual variability}

With the retreat of the summer monsoon and the invasion of cold air, soil in the eastern Tibetan Plateau, north of northwestern and northeastern China, begins to freeze in autumn (Fig. 2c). As the air temperature continues to drop, the freezing depth increases and is more than $1 \mathrm{~m}$ in northeast China. At the same time, the range of frozen soil further expands and reaches a maximum. The southern boundary can reach the Yangtze River region in winter (Fig. 2d). As the air temperature gradually increases in spring, the southern boundary of the frozen soil retreats north of the Yellow River, and the maximum SFD decreases in most regions except northeastern China (Fig. 2a). As the summer approaches, the range of frozen ground further decreases, and the areas of thawing reach a maximum. Only northnortheast China still has some frozen soil (Fig. 2b), slightly more than in autumn.

Soil freezing and thawing processes are generally accompanied by phase transitions of soil water and result in the release and absorption of latent heat (Yang et al. 2007). During summer months, both rain- 

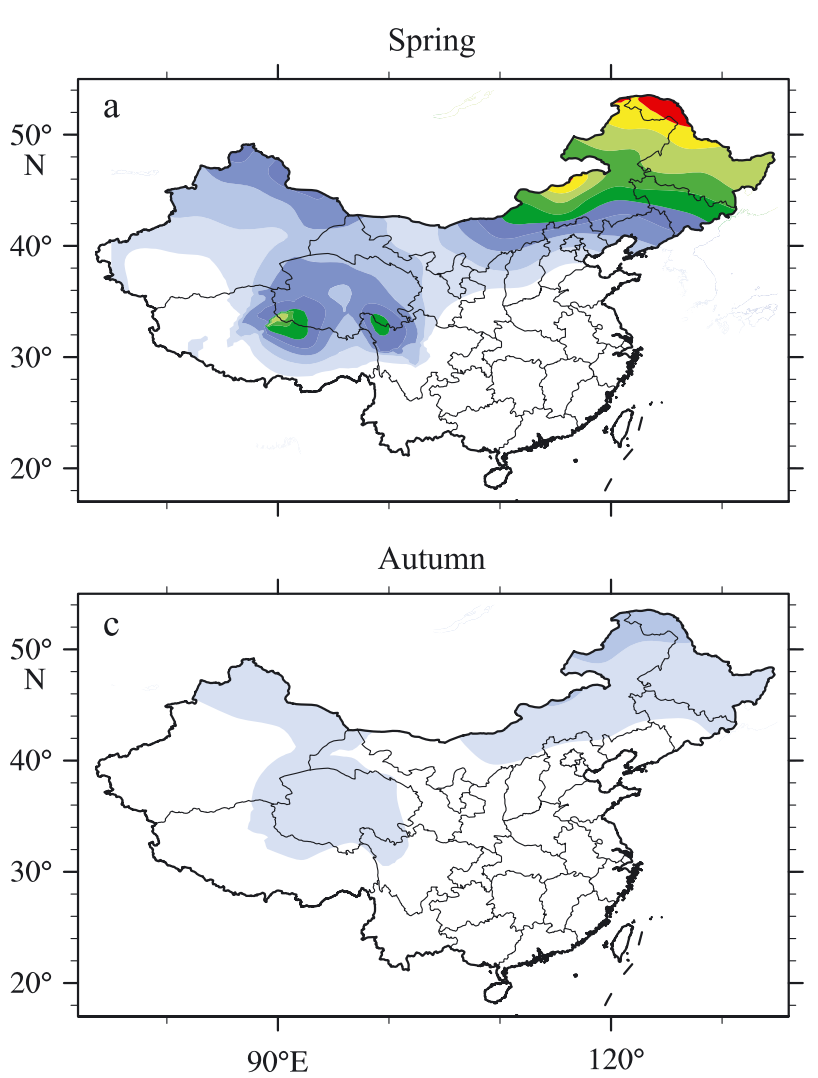
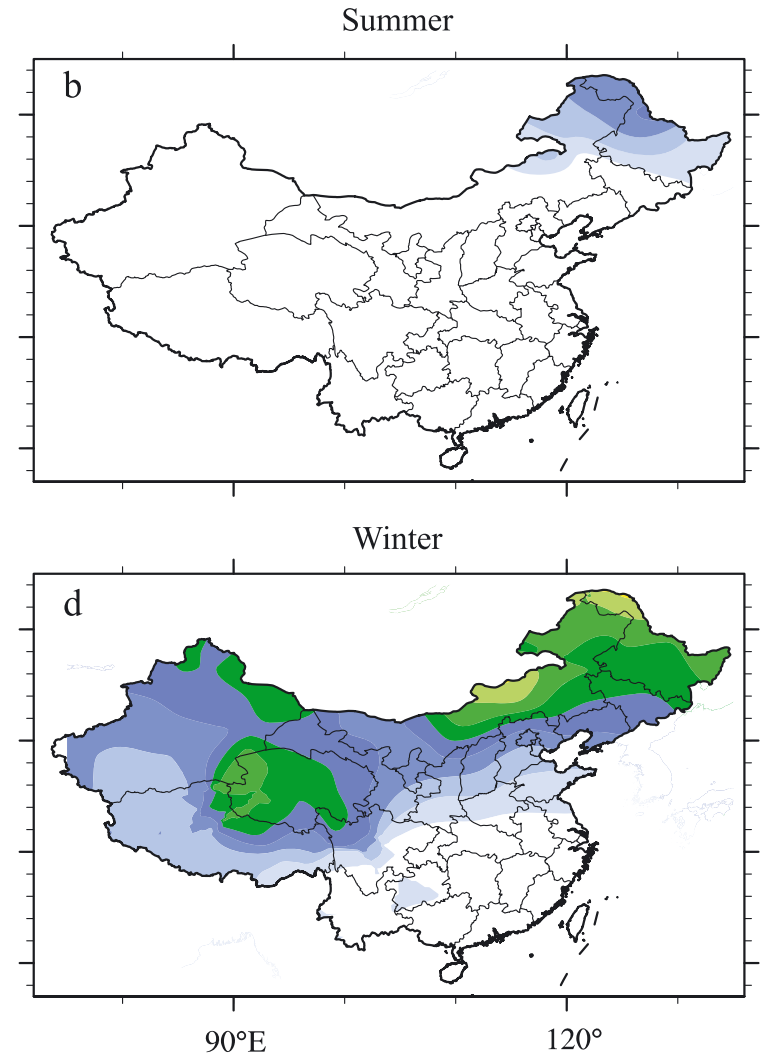

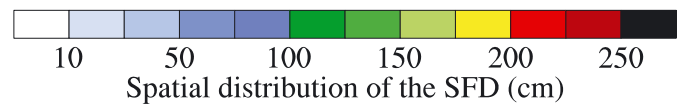

Fig. 2. Spatial distribution of the seasonal freezing depth (SFD; $\mathrm{cm}$ ) across China in (a) spring, (b) summer, (c) autumn and (d) winter during 1965-2013

fall and air temperature in northeastern China reach the maximum of the whole year. The frozen soil continues to melt, which requires a large amount of energy and thus restrains the rise in soil temperature. In addition, the increase in rainfall increases the surface wetness and soil moisture, which results in much more energy consumption for evaporation and cooling the ground surface and soils. Therefore, the thawing of the frozen soil slows. In contrast, during the autumn months, rainfall and air temperature in northeastern China decrease greatly, and evaporation is almost negligible. The soil begins to freeze and releases the latent heat of fusion, which restrains the soil temperature and slows the freezing of the soil. Therefore, the magnitude of the freezing depth in northeastern China is larger in summer than in autumn. In general, the frozen soil in eastern China shows zonal distribution characteristics, and the frozen soil in northwestern China exhibits an obvious vertical zonality due to the complex and diverse terrain.

Fig. 3 shows the trends in SFD $\left(\mathrm{cm} \mathrm{yr}^{-1}\right)$ at each observing station during 1965-2013. The SFD exhib- its a decreasing trend over most of China, with a greater decreasing trend north of northeastern China, north of northwestern China and at a few stations in the Tibetan Plateau. Southeastern China has the lowest decreasing trend, and a few stations even have a weak increasing trend (Fig. 3).

For the whole period, the SFD in the 4 different regions exhibits an obvious change from positive to negative anomalies in approximately 1988 (Fig. 4). The SFD shows a significant decreasing trend at a confidence level of $99 \%$, and the rates of decrease in the 4 sub-regions of E1, E2, W, and TP are (mean \pm $\mathrm{SE}) 0.23 \pm 0.03,0.08 \pm 0.01,0.26 \pm 0.03$ and $0.24 \pm 0.03$ $\mathrm{cm} \mathrm{yr}^{-1}$, respectively. The results agree with those of Peng et al. (2017), except in the E2 region. divided China into 5 zones according to temperature, precipitation and other parameters. Four of the 5 zones are roughly similar to our studied sub-regions, and the decreasing trend reported by Peng et al. (2017) was $0.27,0.01,0.26$ and $0.22 \mathrm{~cm} \mathrm{yr}^{-1}$, corresponding to our sub-regions of E1, E2, W and TP, respectively. In contrast, Wang et al. (2019) reported a decrease in SFD of 


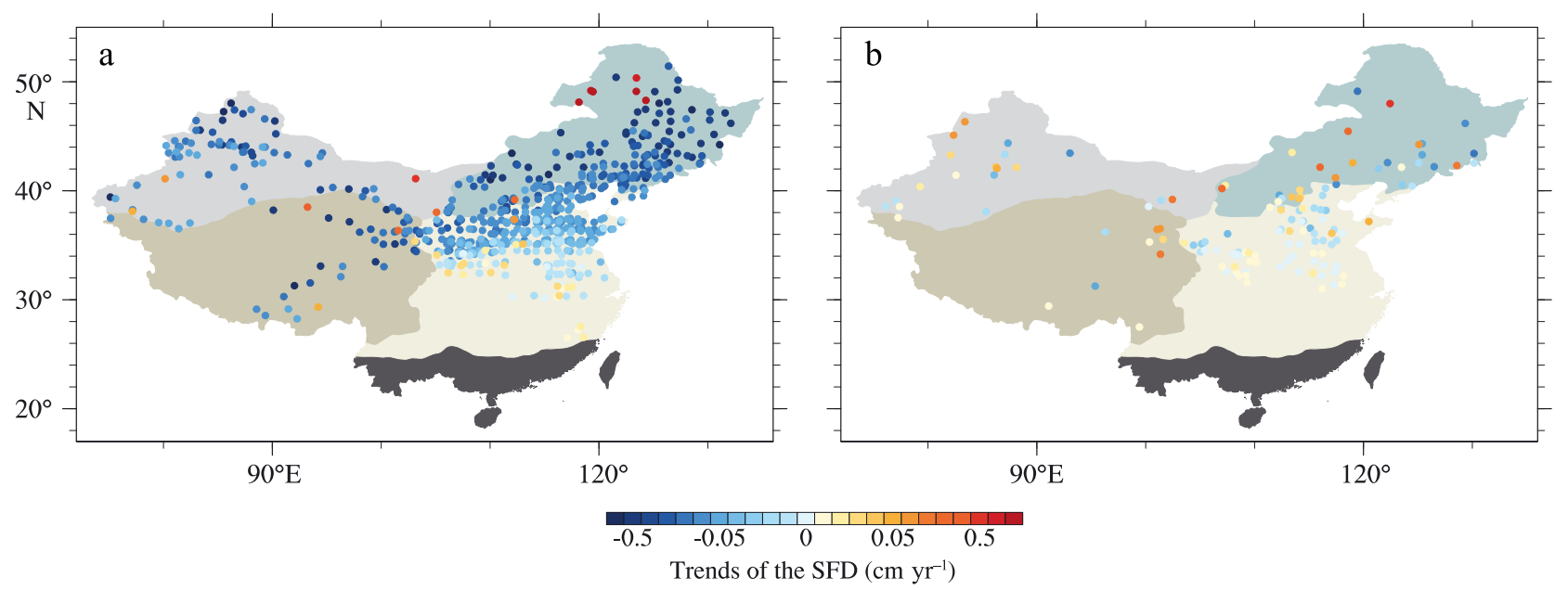

Fig. 3. Trends of the seasonal freezing depth ( $\mathrm{SFD} \mathrm{cm} \mathrm{yr}^{-1}$ ) at each observing station from 1965-2013. (a) Significant and (b) non-significant trends at the $95 \%$ confidence level
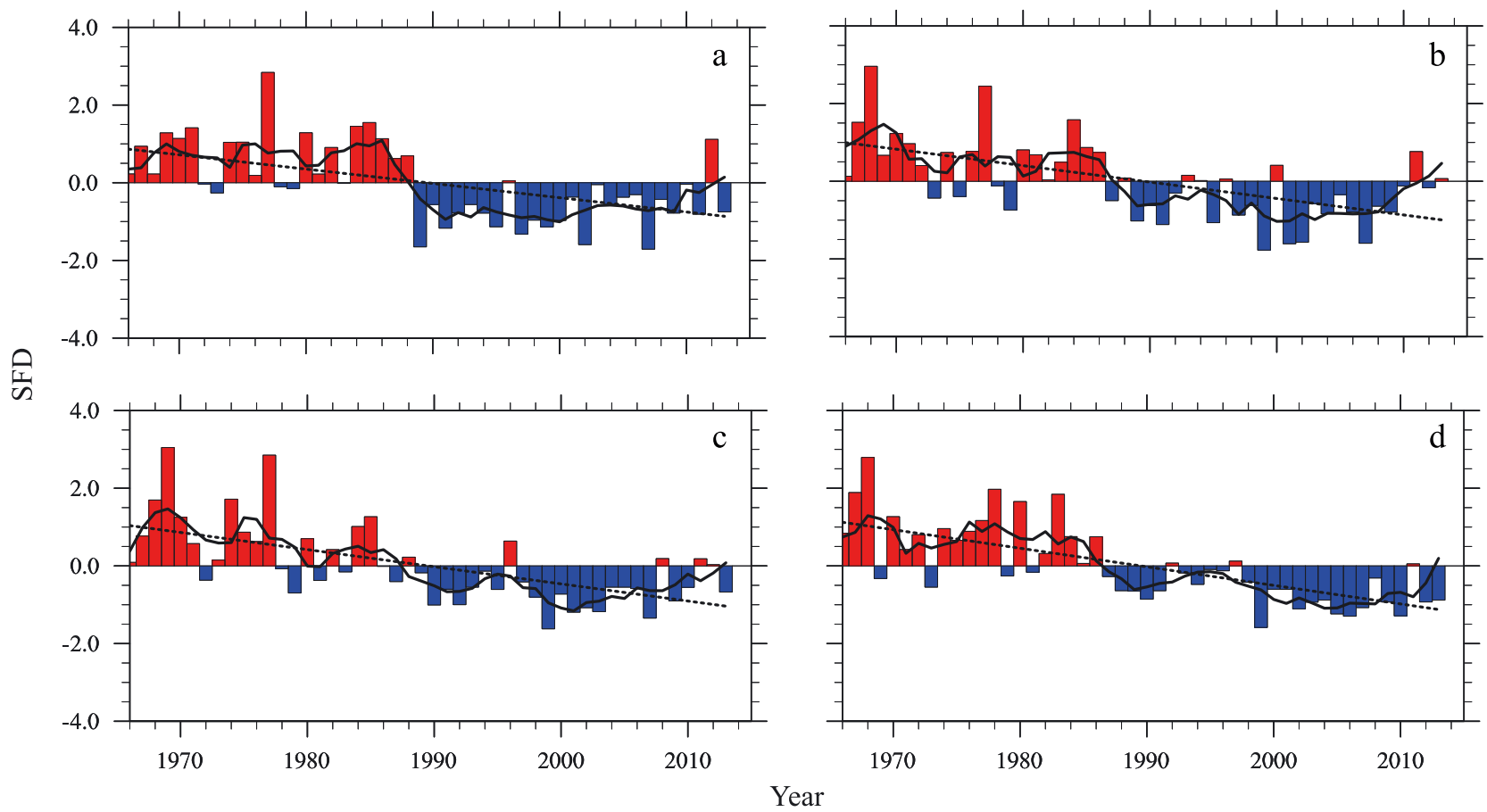

Fig. 4. Inter-annual variations in the maximum seasonal freezing depth (SFD) in regions (a) E1, (b) E2, (c) W and (d) TP (see Fig. 1 for locations). The black solid lines represent 5 yr running means, the black dotted lines represent trends, and the red and blue bars represent annual means

approximately $0.34 \mathrm{~cm} \mathrm{yr}^{-1}$ in $\mathrm{W}, 0.47 \mathrm{~cm} \mathrm{yr}^{-1}$ in the $\mathrm{TP}$ and $0.41 \mathrm{~cm} \mathrm{yr}^{-1}$ in E1 and E2 together, which was significantly higher than our results.

Table 1 shows a comparison between our research and that of Peng et al. (2017) and Wang et al. (2019) in the methods of obtaining the SFD data, the number of observational stations used and the study periods. A previous study verified that the estimated SFD from the Stefan solution has a high correlation with the observations (Wang et al. 2019). Therefore, the large differences in the results among the 3 studies may be related to the density of the observed data. Greater station density provides more representative observations (Table 1).

\subsection{Driving factors of SFD variability}

The correlations of SFD with potential factors, including the winter/summer Temp (Temp_win 
Table 1. Comparisons among 3 studies on seasonal freezing depth (SFD) data sources, the number of observational stations and study periods

\begin{tabular}{|llrc|}
\hline Reference & SFD source & Number of stations & Study period \\
\hline This study & Observed monthly SFD & 764 & $1965-2013$ \\
Peng et al. (2017) & Stefan solution based on the observed daily air temperature and soil temperature & 729 & $1950-2009$ \\
Wang et al. (2019) & Observed daily SFD & 351 & $1961-2010$ \\
\hline
\end{tabular}

Table 2. Trend in seasonal freezing depth (SFD) and 7 potential forcing variables ( \pm SE where applicable) during 1965-2013 in regions E1, E2, W and TP (see Fig. 1 for locations). The symbols ${ }^{* * *}$ and ${ }^{*}$ are the significances of the correlations at the 99 and $90 \%$ confidence level, respectively. Temp: temperature, Pre: precipitation, win: winter, sum: summer, SND: snow depth, FI: freezing index, TI: thawing index

\begin{tabular}{|c|c|c|c|c|}
\hline Variable & E1 & E2 & W & $\mathrm{TP}$ \\
\hline SFD $\left(\mathrm{cm} \mathrm{decade}{ }^{-1}\right)$ & $-2.31^{* * *}$ & $-0.79^{* * *}$ & $-2.55^{* * *}$ & $-2.40^{* * *}$ \\
\hline Temp_win $\left({ }^{\circ} \mathrm{C}\right.$ decade $\left.{ }^{-1}\right)$ & $0.51 \pm 0.09^{* * *}$ & $0.47 \pm 0.05^{* * *}$ & $0.48 \pm 0.08^{* * *}$ & $0.45 \pm 0.04^{* * *}$ \\
\hline Temp_sum $\left({ }^{\circ} \mathrm{C}\right.$ decade $\left.{ }^{-1}\right)$ & $0.34 \pm 0.03^{* * *}$ & $0.11 \pm 0.03^{* * *}$ & $0.26 \pm 0.03^{* * *}$ & $0.33 \pm 0.03^{* * *}$ \\
\hline Pre_win $\left(\mathrm{mm} \mathrm{decade}^{-1}\right)$ & $0.31 \pm 0.06^{* * *}$ & 0.25 & $0.71 \pm 0.08^{* * *}$ & $0.12 \pm 0.04^{* * *}$ \\
\hline Pre_sum (mm decade $\left.{ }^{-1}\right)$ & -0.97 & 0.36 & $0.91 \pm 0.18^{* * *}$ & $0.36 \pm 0.16^{*}$ \\
\hline SND_win $\left(\mathrm{cm} \mathrm{decade}{ }^{-1}\right)$ & $0.47 \pm 0.08^{* * *}$ & $-0.19 \pm 0.05^{* * *}$ & $0.79 \pm 0.12^{* * *}$ & 0.00 \\
\hline FI $\left({ }^{\circ} \mathrm{C} \mathrm{d} \mathrm{yr}^{-1}\right)$ & $-6.56 \pm 1.03^{* * *}$ & $-2.53 \pm 0.31^{* * *}$ & $-5.60 \pm 0.78^{* * *}$ & $-5.52 \pm 0.41^{* * *}$ \\
\hline $\operatorname{TI}\left({ }^{\circ} \mathrm{C} \mathrm{d} \mathrm{yr}{ }^{-1}\right)$ & $6.14 \pm 0.62^{* * *}$ & $6.05 \pm 0.91^{* * *}$ & $8.43 \pm 0.83^{* * *}$ & $7.87 \pm 0.61^{* * *}$ \\
\hline
\end{tabular}

and Temp_sum), winter/summer Pre (Pre_win and Pre_sum), winter SND (SND_win), FI and TI, were calculated to analyse the potential drivers of SFD variability in regions E1, E2, $\mathrm{W}$ and the TP during 1965-2013.

An evident warming trend is observed in all 4 studied regions, and the warming ratio is greatest in winter (Table 2). Temp_win had a more significant negative correlation with SFD than did Temp_sum (Table 3), especially in the E2 region. The correlation between SFD and Temp_win reached -0.9 , and Temp_win accounted for $78.9 \%$ of SFD variability. This means that SFD decreased with increasing winter air temperature.

Both the FI and TI are based on temperature. Specifically, the FI (TI) reflects the combined magnitude and duration of air or surface temperature below (above) freezing during a cold (warm) season. The FI has a high relation with the absolute Temp_win, and the TI is connected closely with the Temp_sum (Table 3). Meanwhile, the FI shows a significant decreasing trend during 1965-2013 (Table 3), for the shortened duration of the near-surface soil freeze across China (Wang et al.
Table 3. Correlation coefficients among the seasonal freezing depth (SFD) and 7 potential forcing variables and among the 7 potential forcing variables in regions E1, E2, W and TP (see Fig. 1 for locations). The symbols ${ }^{* * *}{ }^{* *}$, and ${ }^{*}$ are the significances of the correlations at the 99, 95 and $90 \%$ confidence level, respectively. Variables are defined in Table 2

\begin{tabular}{|c|c|c|c|c|c|c|c|}
\hline Region & Temp_win & Temp_sum & Pre_win & Pre_sum & SND_win & FI & TI \\
\hline \multicolumn{8}{|l|}{ E1 } \\
\hline SFD & $-0.68^{* * *}$ & $-0.45^{* * *}$ & $-0.32^{* *}$ & $0.25^{*}$ & $-0.36^{* *}$ & $0.73^{* * *}$ & $-0.47^{* * *}$ \\
\hline Temp_win & & $0.35^{* *}$ & -0.04 & -0.21 & $0.24^{*}$ & $-0.94^{* * *}$ & $0.26^{*}$ \\
\hline Temp_sum & & & -0.09 & -0.17 & 0 & $-0.49^{* * *}$ & $0.67^{* * *}$ \\
\hline Pre_win & & & & -0.09 & $0.76^{* * *}$ & 0.02 & 0.19 \\
\hline Pre_sum & & & & & 0.01 & 0.19 & -0.10 \\
\hline SND_win & & & & & & 0.22 & 0.36 \\
\hline FI & & & & & & & $-0.27^{*}$ \\
\hline \multicolumn{8}{|l|}{ E2 } \\
\hline SFD & $-0.90^{* * *}$ & -0.37 & -0.36 & 0.04 & 0 & $0.91^{* * *}$ & $-0.45^{* * *}$ \\
\hline Temp_win & & $0.32^{* *}$ & 0.18 & 0.04 & $-0.29^{* *}$ & $-0.97^{* * *}$ & $0.44^{* * *}$ \\
\hline Temp_sum & & & 0.01 & -0.16 & -0.14 & $-0.26^{*}$ & $0.83^{* * *}$ \\
\hline Pre_win & & & & 0.18 & $0.67^{* * *}$ & -0.19 & 0.05 \\
\hline Pre_sum & & & & & 0.09 & -0.10 & -0.13 \\
\hline SND_win & & & & & & 0.22 & -0.19 \\
\hline FI & & & & & & & $-0.37^{* * *}$ \\
\hline \multicolumn{8}{|l|}{$\mathbf{W}$} \\
\hline SFD & $-0.81^{* * *}$ & $-0.32^{* *}$ & $-0.36^{* *}$ & $-0.41^{* * *}$ & -0.20 & $0.84^{* * *}$ & $-0.38^{* * *}$ \\
\hline Temp_win & & 0.15 & 0.15 & $0.31^{* *}$ & -0.13 & $-0.95^{* * *}$ & 0.17 \\
\hline Temp_sum & & & 0.04 & 0 & 0.09 & $-0.30^{* *}$ & $0.79^{* * *}$ \\
\hline Pre_win & & & & $0.33^{* *}$ & $0.79^{* * *}$ & -0.12 & $0.33^{* *}$ \\
\hline Pre_sum & & & & & $0.25^{*}$ & $-0.34^{* *}$ & -0.03 \\
\hline SND_win & & & & & & 0.20 & $0.37^{* *}$ \\
\hline FI & & & & & & & $-0.26^{*}$ \\
\hline \multicolumn{8}{|l|}{ TP } \\
\hline SFD & $-0.88^{* * *}$ & $-0.64^{* * *}$ & -0.13 & -0.08 & 0.17 & $0.92^{* * *}$ & $-0.74^{* * *}$ \\
\hline Temp_win & & $0.60^{* * *}$ & -0.04 & 0.02 & $-0.29^{* *}$ & $-0.98^{* * *}$ & $0.75^{* * *}$ \\
\hline Temp_sum & & & 0.04 & 0.19 & -0.12 & $-0.69^{* * *}$ & $0.82^{* * *}$ \\
\hline Pre_win & & & & 0.18 & $0.86^{* * *}$ & -0.10 & 0.11 \\
\hline Pre_sum & & & & & 0.14 & -0.03 & 0.05 \\
\hline SND_win & & & & & & $0.27^{*}$ & -0.13 \\
\hline FI & & & & & & & $-0.80^{* * *}$ \\
\hline
\end{tabular}


2015) and warming trend in the Temp_win, which is not beneficial to the preservation of frozen soil. There are much higher positive correlations between the FI and SFD, for which the correlation coefficients are more than 0.7 and even up to 0.9 in E2 and TP (Table 3). The FI accounted for 82.6 and $84.9 \%$ of the SFD variability in $\mathrm{E} 2$ and $\mathrm{TP}$, respectively.

SND_win exhibits a decreasing trend $(-0.19 \pm 0.05$ $\mathrm{cm}$ decade $^{-1}$ ) in E2 and a clearly increasing trend in E1 $\left(0.47 \pm 0.08 \mathrm{~cm} \mathrm{decade}^{-1}\right)$ and W $(0.79 \pm 0.12 \mathrm{~cm}$ decade $\left.^{-1}\right)$. The TP region shows almost no trend. There is a significantly negative correlation between SND_win and SFD in E1 (Table 2), and approximately $13 \%$ of the SFD variability can be accounted for by SND_win, which indicates that the SFD decreased as the SND_win increased in the E1 region. As Zhang (2005) suggested, the snow insulating effect would increase with snow thickness until the snow thickness reaches $40 \mathrm{~cm}$. In the E1 region, the SND_win is generally $<40 \mathrm{~cm}$. Therefore, with thicker snow, the snow insulating effect will increase, resulting in a warmer soil surface, which will ultimately lead to a decrease in the SFD. However, SND_win has no notable dependence on SFD in the E2, $\mathrm{W}$ and TP regions. PRE_win has a strong positive correlation with SND_win in all 4 regions; meanwhile, in the $\mathrm{W}$ region, Pre_win has a notable negative correlation with SFD and accounts for nearly $11 \%$ of the SFD variability.

The variation in SFD may be the combined result of several factors, so we checked the combined effect of these variables (Temp_win, Temp_sum, Pre_win, Pre_sum, SND_win, FI and TI) on SFD. In E2 and TP, just the contribution of FI to the change in SFD reaches 82.6 and $84.9 \%$, respectively, so FI is the main impact factor in E2 and TP. In E1, SND_win and

Correlation coefficients between EAWMI and SFD

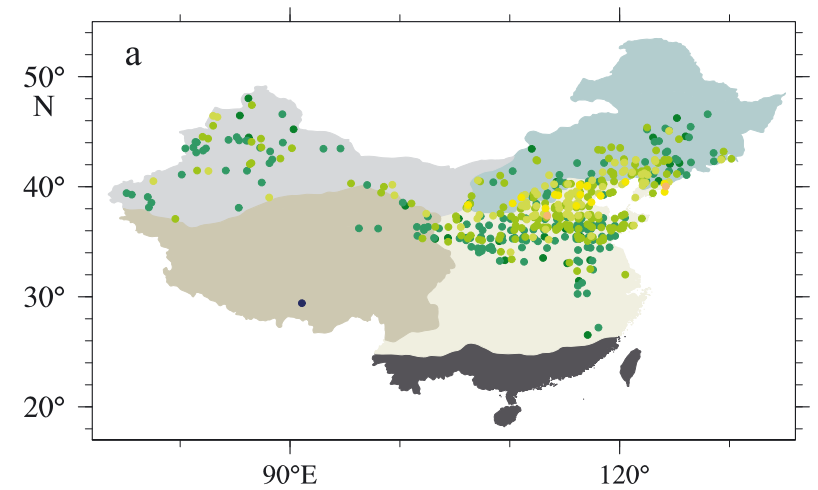

$\begin{array}{lllllll}0.9 & -0.6 & -0.3 & 0 & 0.3 & 0.6 & 0.9\end{array}$

Correlation coefficient
FI account for $81.7 \%$ of the variability in SFD, and the contribution of SND_win to the variability in SFD is the largest (51.8\%), followed by that of FI $(48.2 \%)$, according to Eqs. (1) and (2). Thus, increased SND_win almost doubles the decrease in SFD caused by increasing FI. However, in $\mathrm{W}$, the main factors that affect changes in SFD are Pre_win and FI, which account for $76.8 \%$ of the SFD variability. FI $(67.6 \%)$ is the main contributor to the change in SFD, followed by Pre_win (32.4\%). Previous work (Wang et al. 2015, Peng et al. 2017) showed that SND_win has almost no relationship with SFD across China, but our results indicate that the influence of SND_win and snowfall on SFD is not ignorable for the snowy areas (E1 and W). SND_win not only has strong correlations with $\mathrm{SFD}$, but plays the primary role in changes in SFD over the E1 region and may be related to the high spatial heterogeneity of SND and SFD across China. Therefore, it is necessary to divide China into different regions to analyze and predict changes in SFD.

In general, both the magnitude of temperature below $0^{\circ} \mathrm{C}$ and its duration during the cold season are the main factors for the change in the SFD in the TP and E2 regions. For E1, SND_win plays a leading role in changing SFD, while FI is secondary. However, both FI and Pre_win are crucial for the SFD variability in the $\mathrm{W}$ region, with FI accounting for most of the difference.

\subsection{Large-scale circulations}

Fig. 5 shows the spatial distributions of the correlation between SFD and EAWMI and NAO. SFD has a positive correlation with EAWMI at 484 of the 764

Correlation coefficients between NAO and SFD

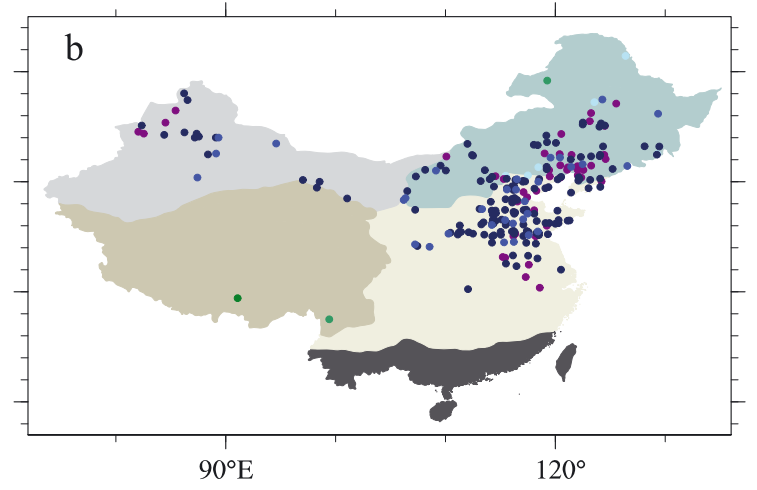$$
120^{\circ}
$$

Fig. 5. Spatial distributions of the correlation coefficients between the SFD and (a) the East Asian winter monsoon index (EAWMI) and (b) the North Atlantic Oscillation (NAO) at the $95 \%$ confidence level 
stations at the $95 \%$ confidence level, with 120 stations located in E1, 292 stations in E2, 57 stations in $\mathrm{W}$, and 15 stations in TP, separately accounting for $61.5,68.5,62.6$ and $29.4 \%$ of total stations in each region, respectively. Most of the correlation coefficients are approximately $0.3-0.5$, but some reach 0.7 .
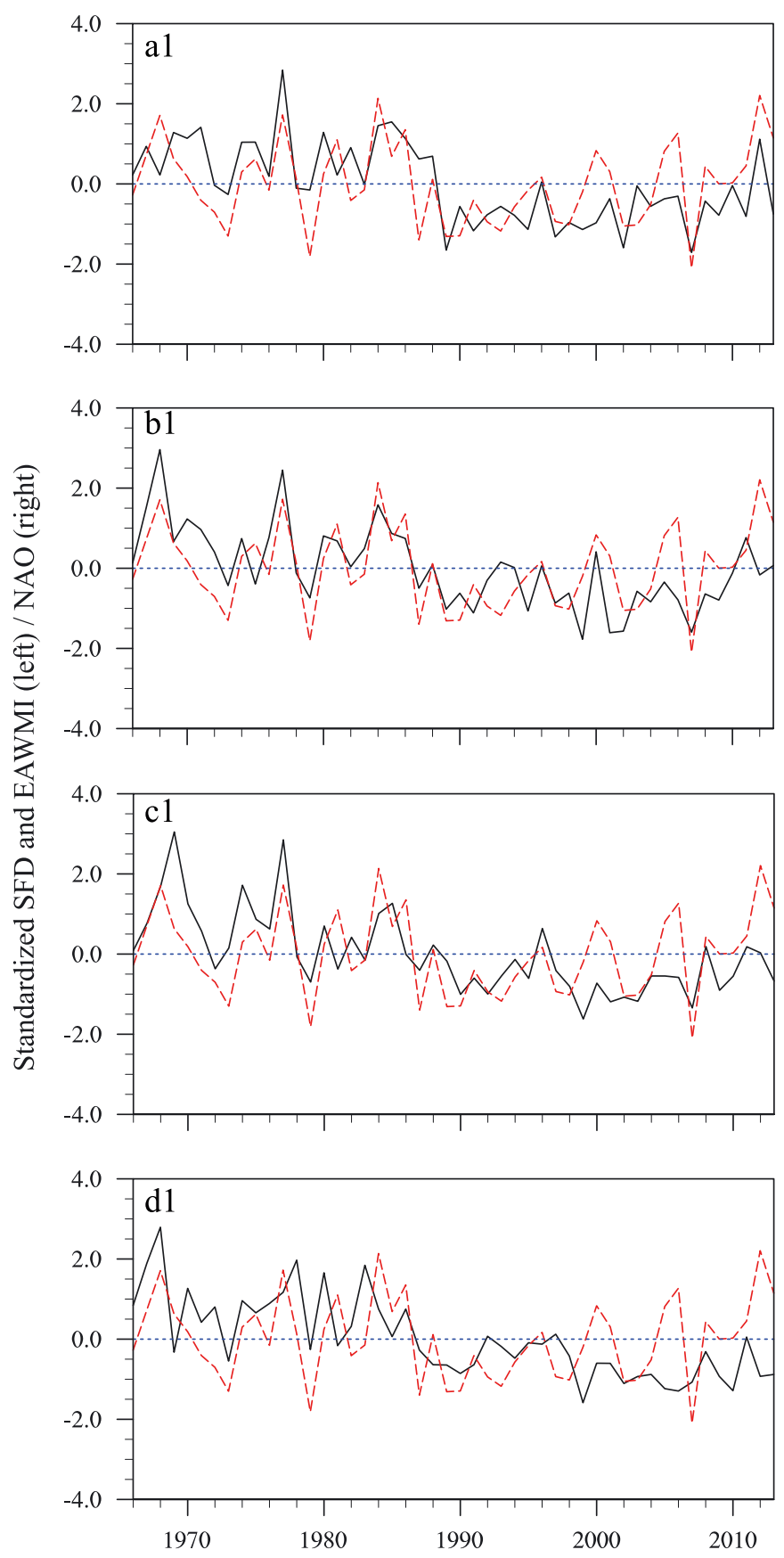

For each region, correlating the SFD time series with EAWMI produces a positive correlation in E1 $(\mathrm{R}=$ $0.54), E 2(R=0.58), W(R=0.50)$ and $T P(R=0.29)$ at the $95 \%$ confidence level (Fig. 6). Significantly, during 1965-1999, the correlation coefficients of EAWMI with SFD exceed 0.65 in all research regions except
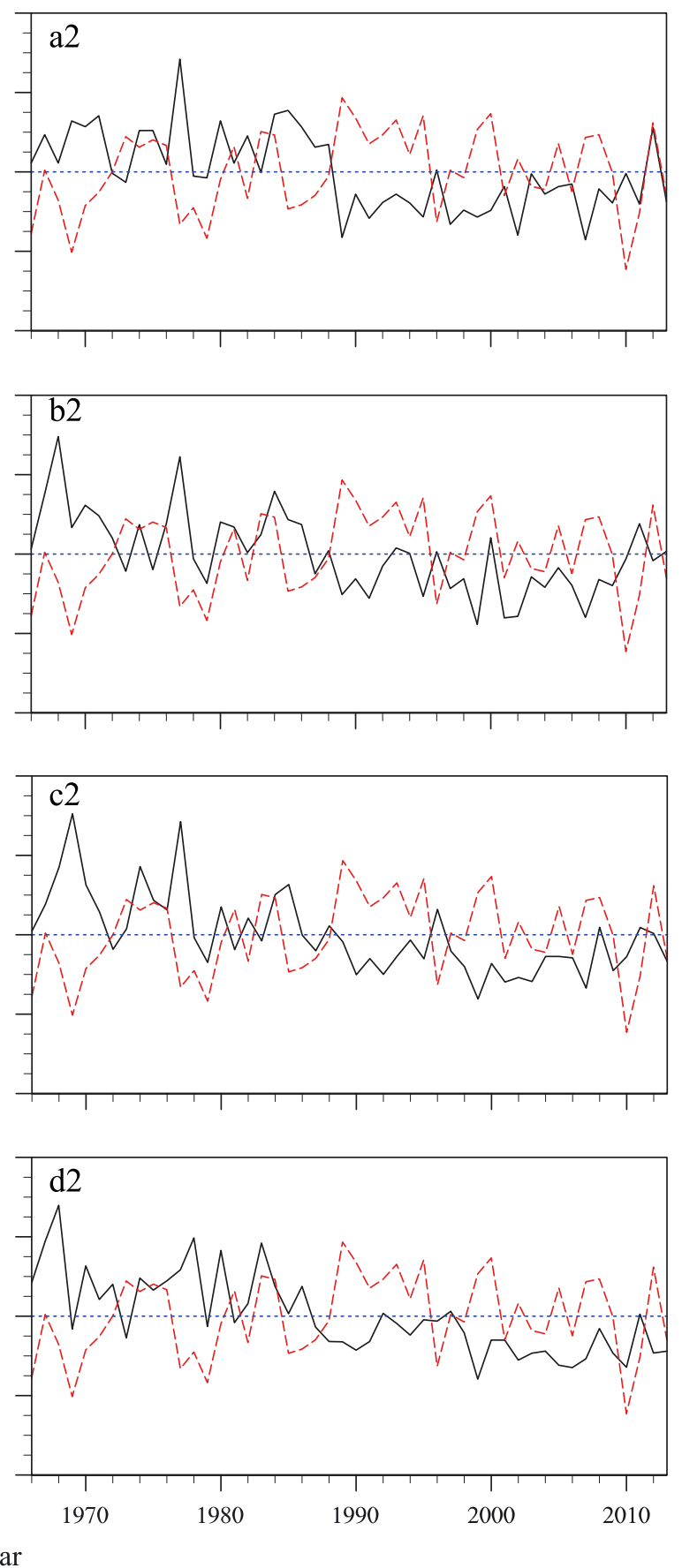

Fig. 6. Time series of standardized seasonal freezing depth (SFD; black line) and standardized East Asian winter monsoon index (EAWMI; left column, red line) and North Atlantic Oscillation (NAO; right column, red line) indicating the correspondence over 1965-2013 for regions $(\mathrm{a} 1, \mathrm{a} 2) \mathrm{E} 1,(\mathrm{~b} 1, \mathrm{~b} 2) \mathrm{E} 2,(\mathrm{c} 1, \mathrm{c} 2) \mathrm{W}$ and $(\mathrm{d} 1, \mathrm{~d} 2) \mathrm{TP}$ (see Fig. 1 for locations). 1 and 2 indicate the EAWMI and NAO, respectively 
the TP. Especially in the E2 region, the correlation reaches 0.78 , and EAWMI accounts for $52 \%$ of SFD variability in E2. In addition, EAWM shows a transition from a relative strong to a weak regime around 1986/1987, which is consistent with previous studies (Jhun \& Lee 2004, Wang \& Chen 2014, Yun et al. 2018) and the SFD series. Numerous studies have shown that the weakening of EAWM around the mid1980s coincides with the rapid warming of winter temperatures over East Asia, and considered the global warming and the interdecadal variations in the ocean as the most important factors influencing the weakening of EAWM, which may be the reasons for the shift of SFD around the same time (Hori \& Ueda 2006, Ding et al. 2014). As described in Section $3.2, \mathrm{FI}$ is the main factor for the change in SFD in most regions. The stronger (weaker) EAWM with a colder (warmer) winter temperature corresponds to relatively large (small) $\mathrm{FI}$; therefore, there are strong correlations between the EAWM and SFD in all studied regions.

We further examined the relationship between the winter NAO and SFD from spatial and temporal scales. The result shows that the winter NAO has negative correlations with SFD, with 241 stations passing the $95 \%$ confidence test, i.e. nearly half the number of stations showing significant correlations with the EAWM (Fig. 5). The correlation coefficients of the winter NAO with SFD during 1965-2013 are $-0.40,-0.29$ and -0.35 in the E1, E2 and W regions, respectively, while there are no significant correlations in the TP region (Fig. 6). Compared to EAWM, the winter NAO has weaker correlation with SFD. Previous studies have suggested that the winter NAO directly influences the winter temperature in the region north of $35^{\circ} \mathrm{N}$ in East Asia, especially the northeast and northwest of China, which is probably why NAO has relative stronger correlations with SFD in E1 and W than in E2. Meanwhile, NAO also indirectly influences the winter air temperature through impacting the Siberian high and EAWM (Wu \& Wang 2002, Pokorná \& Huth 2015). This may be one of the reasons for the EAWM having a greater impact on SFD than NAO in China.

\section{CONCLUSIONS}

This study analysed the climatology and variability in SFD in seasonally frozen regions of China during 1965-2013 by using observational data of the maximum SFD. We also investigated the connections between changes in SFD and meteorological factors
(Temp, Pre, SND, FI and TI), and atmospheric circulations (EAWM and NAO) in each sub-region (E1, E2, $\mathrm{W}$ and TP). The main results can be summarized as follows.

Against a background of global warming, SFD in each sub-region exhibits a significant decreasing trend, namely $0.23 \pm 0.03,0.08 \pm 0.01,0.26 \pm 0.03$ and $0.24 \pm 0.03 \mathrm{~cm} \mathrm{yr}^{-1}$ in E1, E2, W and TP, respectively, reflecting regional disparities. In addition, SFD has an obvious change from positive to negative anomalies in the mid-1980s in all studied regions, which is consistent with the EAWM.

One of key findings of this study is that the impact of SND_win on the SFD variability across China is spatially heterogeneous, which necessitates dividing the country into different regions to analyse and predict the changes in SFD. SND_win has no relationship with SFD changing in W, E2 and TP, while it shows a significant association in the E1 region, where SND_win and FI together account for $81.7 \%$ of the variability in SFD. The contribution of SND_win and FI to changes in SFD in E1 illustrates that increasing SND_win almost doubles the decrease in SFD caused by increasing FI. However, in the W region, Pre_win and FI account for $76.8 \%$ of the SFD variability, with FI (67.6\%) being the main contributor. For E2 and TP, FI has a strong correlation with SFD, accounting for 82.6 and $84.9 \%$ of the change in the SFD, respectively, which indicates that the magnitude and duration of air or surface temperature below freezing during a cold season play a dominant role in changing SFD for E2 and TP regions. In addition, our research shows that EAWM has a greater correlation with SFD than NAO does. The correlation coefficient of EAWMI with SFD reaches 0.78 in E2 during 1965-1999, and accounts for $52 \%$ of the SFD variability. These findings, which indicate that SFD is susceptible to climate change, have implications for further understanding the mechanisms of cold environment changes across China.

Acknowledgements. This work was supported by the National Key R\&D Program of China (Grant No. 2017YFA0603902) and the National Science Foundation for Young Scientists of China (Grant No. 41505080). We thank the CMA for providing the observational data.

\section{LITERATURE CITED}

Chen B, Li J (2008) Characteristics of spatial and temporal variation of seasonal and short-term frozen soil in China in recent 50 years. Chin J Atmos Sci 32:432-433

Cheng S, Guan X, Huang J, Ji F, Guo R (2015) Long-term trend and variability of soil moisture over East Asia. J Geophys Res Atmos 120:8658-8670 
China Meteorological Administration (2007) Specifications for surface meteorological observation, Part 14: Measurement of frozen soil. China Meteorological Press, Beijing

Cuo L, Zhang YX, Bohn TJ, Zhao L, Li JL, Liu QM, Zhou BR (2015) Frozen soil degradation and its effects on surface hydrology in the northern Tibetan Plateau. J Geophys Res Atmos 120:8276-8298

₹ Dankers R, Burke EJ, Price J (2011) Simulation of permafrost and seasonal thaw depth in the JULES land surface scheme. Cryosphere 5:773-790

NDing YH, Liu YJ, Liang SJ, Ma XQ and others (2014) Interdecadal variability of the East Asian winter monsoon and its possible links to global climate change. J Meteorol Res 28:693-713

Dorigo W, de Jeu R, Chung D, Parinussa R, Liu Y, Wagner W, Fernández-Prieto D (2012) Evaluating global trends (1988-2010) in harmonized multi-satellite surface soil moisture. Geophys Res Lett 39:L18405

Flerchinger GN, Saxton KE (1989) Simultaneous heat and water model of a freezing snow-residue-soil system I. Theory and development. Trans ASAE 32:565-571

Frauenfeld OW, Zhang T (2011) An observational 71-year history of seasonally frozen ground changes in the Eurasian high latitudes. Environ Res Lett 6:044024

Frauenfeld OW, Zhang T, Barry RG, Gilichinsky D (2004) Interdecadal changes in seasonal freeze and thaw depths in Russia. J Geophys Res Atmos 109:D05101

Frauenfeld OW, Zhang T, McCreight JL (2007) Northern hemisphere freezing/thawing index variations over the twentieth century. Int J Climatol 27:47-63

* Gao R, Wei Z, Dong W, Zhong HL (2005) Impact of the anomalous thawing in the Tibetan Plateau on summer precipitation in China and its mechanism. Adv Atmos Sci 22:238-245

Hori ME, Ueda H (2006) Impact of global warming on the East Asian winter monsoon as revealed by nine coupled atmosphere-ocean GCMs. Geophys Res Lett 33:L03713

Huang W, Wang B, Wright JS (2016) A potential vorticitybased index for the East Asian winter monsoon. J Geophys Res Atmos 121:9382-9399

Hurrell JW (1995) Decadal trends in the North Atlantic oscillation: regional temperatures and precipitation. Science 269:676-679

Jhun JG, Lee EJ (2004) A new East Asian winter monsoon index and associated characteristics of the winter monsoon. J Clim 17:711-726

Li Q, Chen H (2013) Variation of seasonal frozen soil in East China and their association with monsoon activity under the background of global warming. Clim Chang Res Lett 2:47-53

* Li R, Zhao L, Ding YJ (2012) Temporal and spatial variations of the active layer along the Qinghai-Tibet highway in a permafrost region. Chin Sci Bull 57:4609-4616

* Luo D, Jin H, Jin R, Yang X, Lü L (2014) Spatiotemporal variations of climate warming in northern Northeast China as indicated by freezing and thawing indices. Quat Int 349:187-195

Nelson FE (2003) (Un)frozen in time. Science 299:1673-1675

Nelson FE, Anisimov OA, Shiklomanov NI (2001) Subsidence risk from thawing permafrost. Nature 410: 889-890

Nicolsky DJ, Romanovsky VE, Alexeev VA, Lawrence DM (2007) Improved modeling of permafrost dynamics in a GCM land-surface scheme. Geophys Res Lett 34:L08501
Park H, Sherstiukov AB, Fedorov AN, Polyakov IV, Walsh JE (2014) An observation-based assessment of the influences of air temperature and snow depth on soil temperature in Russia. Environ Res Lett 9:064026

* Park H, Fedorov AN, Zheleznyak MN, Konstantinov PY, Walsh JE (2015) Effect of snow cover on pan-Arctic permafrost thermal regimes. Clim Dyn 44:2873-2895

Peng X, Frauenfeld OW, Cao B, Wang K and others (2016) Response of changes in seasonal soil freeze/thaw state to climate change from 1950 to 2010 across China. J Geophys Res Earth Surf 121:1984-2000

* Peng X, Zhang T, Frauenfeld OW, Wang K and others (2017) Response of seasonal soil freeze depth to climate change across China. Cryosphere 11:1059-1073

* Pokorná L, Huth R (2015) Climate impacts of the NAO are sensitive to how the NAO is defined. Theor Appl Climatol 119:639-652

*Polyakov IV, Bekryaev RV, Alekseev GV, Bhatt US and others (2003) Variability and trends of air temperature and pressure in the maritime Arctic, 1875-2000. J Clim 16: 2067-2077

* Rawlins MA, Nicolsky DJ, McDonald KC, Romanovsky VE (2013) Simulating soil freeze/thaw dynamics with an improved pan-Arctic water balance model. J Adv Model Earth Syst 5:659-675

* Sheffield J, Wood EF (2008) Global trends and variability in soil moisture and drought characteristics, 1950-2000, from observation-driven simulations of the terrestrial hydrologic cycle. J Clim 21:432-458

* Shiklomanov NI (2012) Non-climatic factors and long-term, continental-scale changes in seasonally frozen ground. Environ Res Lett 7:011003

* Shukla J, Mintz Y (1982) Influence of land-surface evapotranspiration on the earth's climate. Science 215:1498-1501

* Singh KK, Mishra VD, Sood S, Kumar M (2013) 3-decadal changes in sea ice melting and freezing pattern in Antarctica using SSM/I data. J Indian Soc Remote Sens 41:947-956

* Slater AG, Lawrence DM (2013) Diagnosing present and future permafrost from climate models. J Clim 26: 5608-5623

Wang K, Zhang T, Zhong X (2015) Changes in the timing and duration of the near-surface soil freeze/thaw status from 1956 to 2006 across China. Cryosphere 9:1321-1331

*Wang L, Chen W (2014) The East Asian winter monsoon: reamplification in the mid-2000s. Chin Sci Bull 59:430-436

*Wang L, Yuan X, Xie Z, Wu P, Li Y (2016) Increasing flash droughts over China during the recent global warming hiatus. Sci Rep 6:30571

* Wang X, Chen R, Liu G, Yang Y and others (2019) Spatial distributions and temporal variations of the near-surface soil freeze state across China under climate change. Global Planet Change 172:150-158

Wu B, Wang J (2002) Winter Arctic Oscillation, Siberian high and East Asian winter monsoon. Geophys Res Lett 29:1897

*Wu T, Wang Q, Zhao L, Batkhishig O, Watanabe M (2011) Observed trends in surface freezing/thawing index over the period 1987-2005 in Mongolia. Cold Reg Sci Technol 69:105-111

* Xia K, Luo Y, Li W (2011) Simulation of freezing and melting of soil on the northeast Tibetan Plateau. Chin Sci Bull 56: 2145-2155

F Yang M, Yao T, Gou X, Hirose N, Fujii HY, Hao L, Levia DF (2007) Diurnal freeze/thaw cycles of the ground surface on the Tibetan Plateau. Chin Sci Bull 52:136-139 
Yun J, Ha K, Jo Y (2018) Interdecadal changes in winter surface air temperature over East Asia and their possible causes. Clim Dyn 51:1375-1390

Zhang LX, Jiang LM, Chai LN (2011) Research advances in passive microwave remote sensing of freeze-thaw processes over complex landscapes. Diqiu Kexue Jinzhan 26:1023-1029 (in Chinese)

Zhang TJ (2005) Influence of the seasonal snow cover on the ground thermal regime: an overview. Rev Geophys 43: RG4002

Zhang TJ, Barry RG, Gilichinsky D, Bykhovets SS, Sorokovikov VA, Ye J (2001) An amplified signal of climatic change in soil temperatures during the last century at Irkutsk, Russia. Clim Change 49:41-76

Editorial responsibility: Guoyu Ren,

Beijing, PR China
Zhang ZQ, Hou MT, Wu QB, Gao SR (2019) Historical changes in the depth of seasonal freezing of 'Xing'anling-Baikal' permafrost in China. Reg Environ Change 19:451-460

Zhao TJ, Zhang LX, Jiang LM (2011) A new soil freeze/thaw discriminant algorithm using AMSR-E passive microwave imagery. Hydrol Processes 25: 1704-1716

Zhou YW, Guo DX, Qiu GQ, Cheng GD, Li SD (2000a) Geocryology in China. Science Press, Beijing

Zhou YW, Guo DX, Qiu GQ (2000b) Geocryological regionalization and classification map of the frozen soil in China $(1: 10,000,000)$. National Tibetan Plateau Data Center, doi:10.11888/Geocry.tpdc.270037

Submitted: December 2, 2019; Accepted: April 27, 2020

Proofs received from author(s): June 1, 2020 